\title{
A STUDY OF MICROTREMOR HVSR IN THE RIO-ANTIRIO AREA, (GREECE)
}

\author{
Norda M.E. ${ }^{1}$, Prapiga A. ${ }^{1}$, Paraskevopoulos P. ${ }^{1}$ and Tselentis G.-A. ${ }^{1}$ \\ ${ }^{1}$ University of Patras, Department of Geology, 26504,Rio, Greece, marilianorda@yahoo.gr, \\ annaprapiga@yahoo.gr,paris@upatras.gr,tselenti@noa.gr
}

\begin{abstract}
Horizontal to Vertical Spectral Ratio (HVSR) method has been applied on ambient noise records at the Rio-Antirio area (central Greece). The dataset used was recorded during 7 days by 12 temporary seismic stations deployed in the area. The stations were laid out along a profile and their interval was approximately 500m. The main part of the processing was done using Geopsy software. The aim of this study was to estimate the fundamental frequency at the station sites and its variation with time and azimuth. The processing results showed that for most stations along the profile, the peaks of the HVSR curve are not strong enough and often there are, more than one, peaks, which seem to be persistent during the whole recording time. When taking the azimuth into account, some of the stations show dominant and persistent directions were the HVSR ratio is stronger, while it has been observed that this direction could vary for different frequency peaks of the same stations. Finally, the top sediment layer's geometry and thickness were estimated using Vs velocity results from nearby crosshole measurements.
\end{abstract}

Keywords: Nakamura method, Horizontal to Vertical Spectral Ratio vs Azimuth, fundamental frequency.

\section{Пврі́ $\eta \psi \eta$}

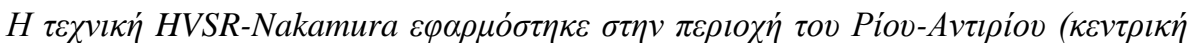

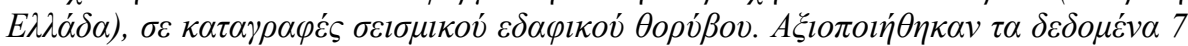

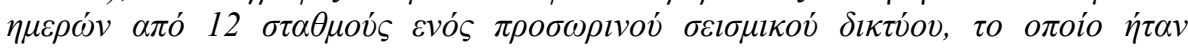

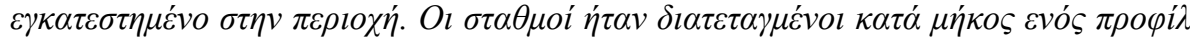

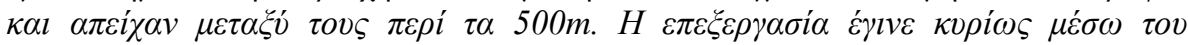

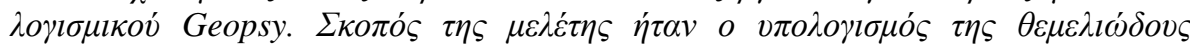

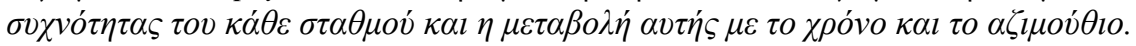

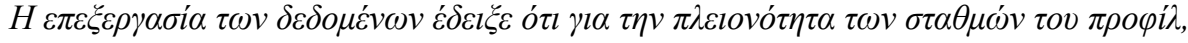

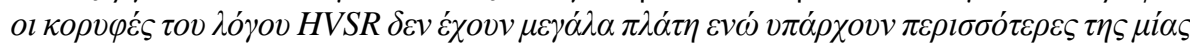

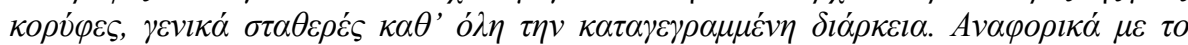

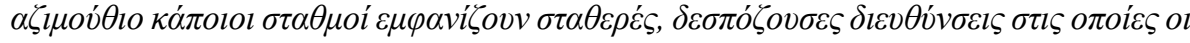

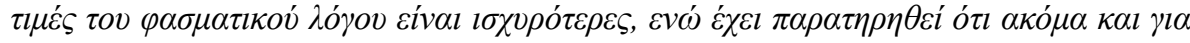

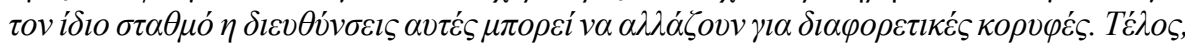

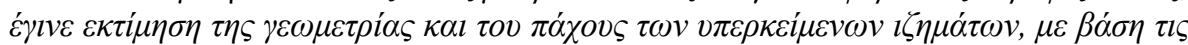

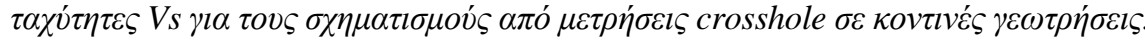

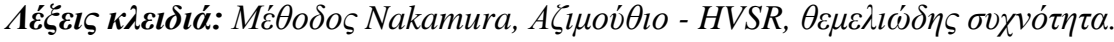




\section{Introduction}

Ambient noise is defined as, the generally low, amplitude vibrations of the Earth's surface that is caused by various sources that can be either natural (such as weather phenomena, sea currents, wind, rain etc.) or anthropogenic (traffic, heavy machinery, urban activity, etc.). The term microtremors, has also been used in the bibliography more or less as synonymous to ambient noise. The HVSR method is used to calculate the dominant frequency, usually, for sedimentary layers in a basin. This information is commonly used for microzoning studies in order to identify possible areas that could amplify earthquake ground motions (Nakamura, 1989, 1997) and has also been used in evaluating the geometry and thickness of sedimentary layers in a basin by examining the variation of the calculated dominant frequency (e.g Oliveto et al., 2004).

In this paper, the application of the Horizontal to Vertical Spectral Ratio (HVSR) method is described as it was applied at the Rio-Antirio area (central Greece). The ambient seismic noise data used were selected, from a previously recorded larger dataset, along a profile consisting of 12 seismic stations with a NNW-SSE orientation.

\section{Area and methodology}

\subsection{Geological characteristics of the area}

The Rio-Antirio strait is located in central Greece, connecting the gulf of Corinth with the gulf of Patras. Across the strait, the Rio Antirion bridge has been constructed, which is an important infrastructure. Corinth gulf is an active rift, in fact it is one of the fastest spreading continental rifts in the world (Avallone et al., 2004). The main fault directions are ENE-WSW and WNW-ESE.

\subsection{Methodology}

The HVSR, method is relatively fast and simple processing is required. The methodology used in order to acquire and process the data is outlined in the following paragraphs.

\subsubsection{Data acquisition}

The data used in this paper were recorded during May 2004, for another seismic experiment that took place in the area (Tselentis et al., 2007). The dataset used for the HVSR study presented here consisted of a subset of 12 stations placed along a profile laid out in a NNW- SSE direction that started from the Antirio area and ended up to Rio across the strait (Figure 1).

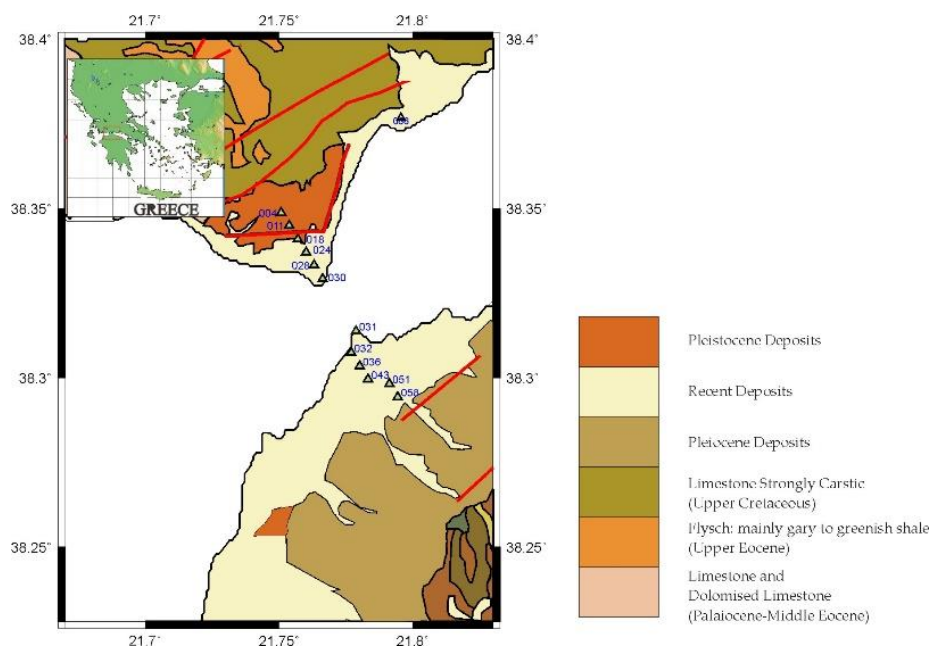

Figure 1 - Layout of the stations used and surface geology. 
The station's distance interval ranged from $500 \mathrm{~m}$ to $800 \mathrm{~m}$ and the time period processed was approximately 7 days. In general, in a HVSR survey, the recording time for each station does not need to be that long and depending on the frequencies studied, can range from several tens of minutes up to several hours. But in this case, taking advantage of the available recorded data, it was possible to evaluate the variability of the spectral ratio's characteristics with time.

The recording equipment, were Earthdata PR24 seismographs. The sensor used was a short period, Landtech S100 3-component seismometer with a flat instrument response from 1 up $70 \mathrm{~Hz}$. The sampling frequency was set to $100 \mathrm{~Hz}$ (Tselentis et al., 2007).

\subsubsection{Processing}

The available ambient noise records were processed using the open source GEOPSY software (www.geopsy.org), while the HVSRmat (Paraskevopoulos, 2015) suite of programs written in matlab were used for data preparation and post processing of the results. Initially the continuous recording was divided in records of 1 hour duration. For each of these records:

- The hourly signal was divided in 30 second windows. Using STA/LTA anti-triggering and visual inspection the windows with high amplitude transient noise were removed.

- For each time window and each component the amplitude spectrum between $0.5-20 \mathrm{~Hz}$ was calculated using FFT.

- Each spectrum was smoothed using the Konno and Ohmachi method (Konno and Ohmachi, 1998) setting the constant $b=40$ in order to avoid any artefacts in the HVSR ratio.

- The HVSR ratio was calculated for each window using Equation 1 and the mean spectral ratio was calculated for each hourly record.

- The mean of all the hourly HVSRs was calculated as the mean HVSR for each station.

\section{Equation 1-HVSR calculation.}

$$
H V S R(f)=\frac{H(f)}{V(f)} \text {. }
$$

Where HVSR(f) is the spectral ratio, V(f) the amplitude spectrum of the vertical component and $\mathrm{H}(\mathrm{f})$ the quadratic mean of the two horizontal components.

The reliability of each hourly curve as well as the reliability of the dominant frequency was evaluated using the SESAME guidelines' criteria (SESAME, 2004).

Additionally it is also possible to calculate the HVSR in relation to the azimuth. As the EW and NS horizontal components were recorded it was possible to calculate the HVSR from $0^{\circ}$ up to $180^{\circ}$ using an interval of $10^{\circ}$. The ratio HVSR from $180^{\circ}$ up to $360^{\circ}$ was symmetric to $0^{\circ}$ up to $180^{\circ}$ so it was not necessary to calculate it.

From the literature it is known that the fundamental frequency is related to the thickness of the top soft sediment layer by Equation 2.

\section{Equation 2- Relation of $f_{0}$ to the thickness of the soft sediment layer.}

$$
f_{0}=\frac{V_{S}}{4 H},
$$

where $f_{0}$ is the fundamental frequency, $\mathrm{V}_{\mathrm{s}}$ the velocity of $\mathrm{S}$ waves and $\mathrm{H}$ is the soft sediment layer thickness. Equation 2 shows that lower frequencies correspond to deeper bedrock. The $\mathrm{V}_{\mathrm{s}}$ velocities used, were approximated based on crosshole measurements made in the vicinity of the Rion - Antirio bridge (CPWL, 1992). Based on this, the $V_{s}$ for Antirio area was set to $300 \mathrm{~m} / \mathrm{sec}$, while for Rio it was $250 \mathrm{~m} / \mathrm{sec}$. 


\section{Results}

\subsection{HVSR ratios of the stations}

HVSR ratio was calculated using up to 168 hourly mean HVSR ratios. The total duration used was relatively long especially compared to the recording durations usually used in these type of measurements, so that any transient low amplitude noise that would affect the measurements and could not be detected visually or by the STA/ LTA anti-triggering, would be cancelled out.

\subsubsection{Antirio}

The first result of the processing was the average HVSR ratios (Figure 2). All the HVSR curves were found to be reliable according to the SESAME criteria (SESAME, 2004). The peaks that can be seen in the HVSR results in the area are weak, having small amplitudes, and almost all stations, except from 24 and partially station 04, fail the peak reliability tests of SESAME. On the other side, the ratio curve form seems to be relatively stable during the whole duration of the measurements. Thus even if HVSR curve peaks vary in amplitude causing the dominant one (the one with the larger amplitude) to vary with time the peaks themselves are persistent in time when observing the overall curve.
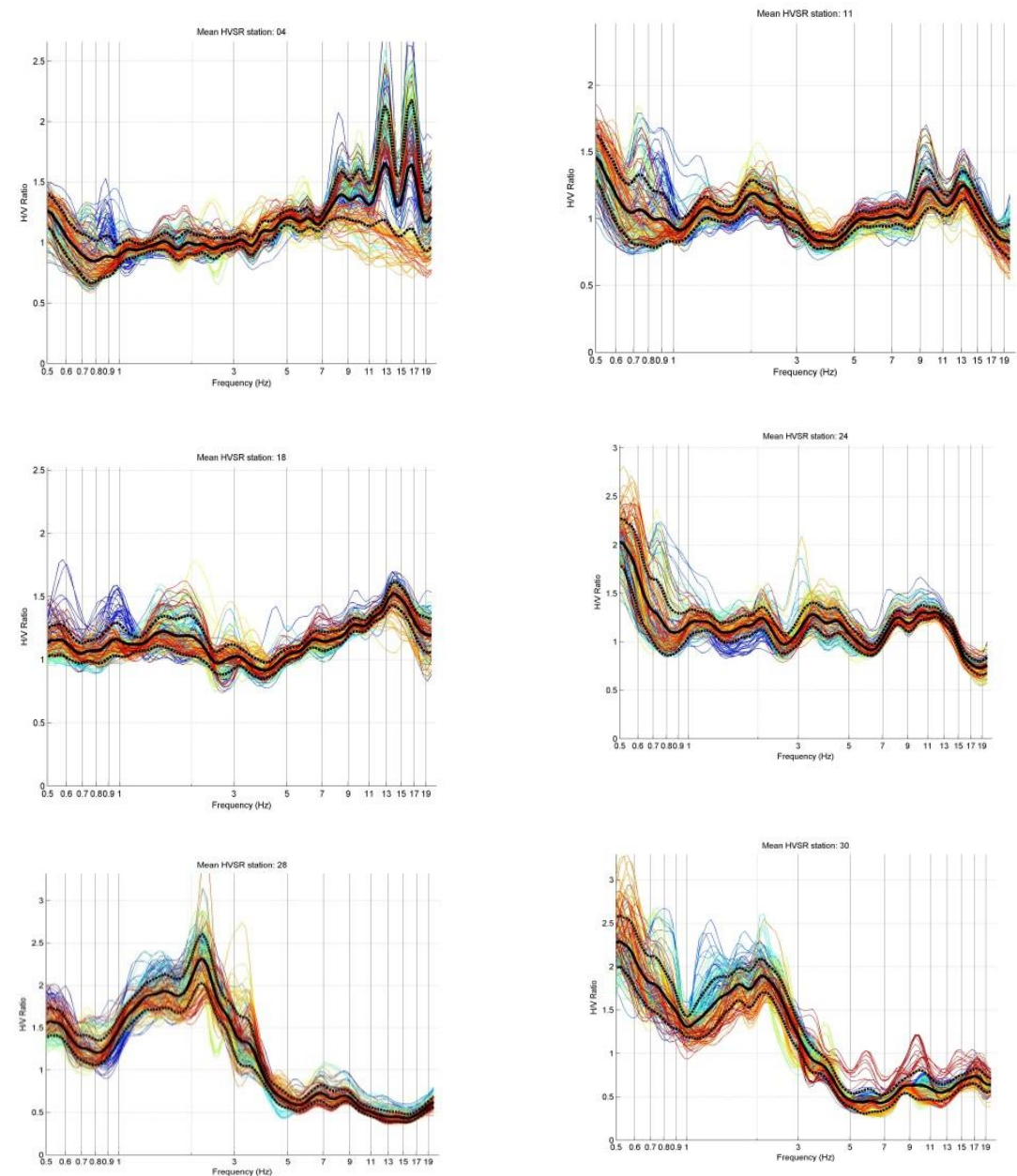

Figure 2 - Mean HVSRs for the Antirio stations. The solid black line is the mean HVSR, the two black dashed lines are the standard deviation while the coloured lines represent the mean hourly HVSRs. 
In the Antirio part, the profile crosses two different geological formations. This change can be seen in the form of the HVSR ratio, which is consistent with the change in geology. Stations 04, 11 and 18, were located on the Pleistocene sediments, while stations 28 and 30 were placed on recent sediments and station 24 was placed near the contact line of the two formations. This is a clear indication that the HVSR ratio is sensitive to the change in the geology.

In summary the following observations could be made:

- Stations 04, 11, 18, and 24 present no clear and/or strong H/V peak that is higher than 2 even though the weak peaks present are persistent with time.

- Stations 28 and 30 exhibit a plateau with slightly higher amplitudes (above 2).

- Rio

In Rio there is no apparent change in geology that can be seen on surface, as all stations were located on recent deposits. Figure 3 presents the HVSR ratio results for the Rio stations. The HVSR curves computed for this dataset were also reliable according to the SESAME criteria.
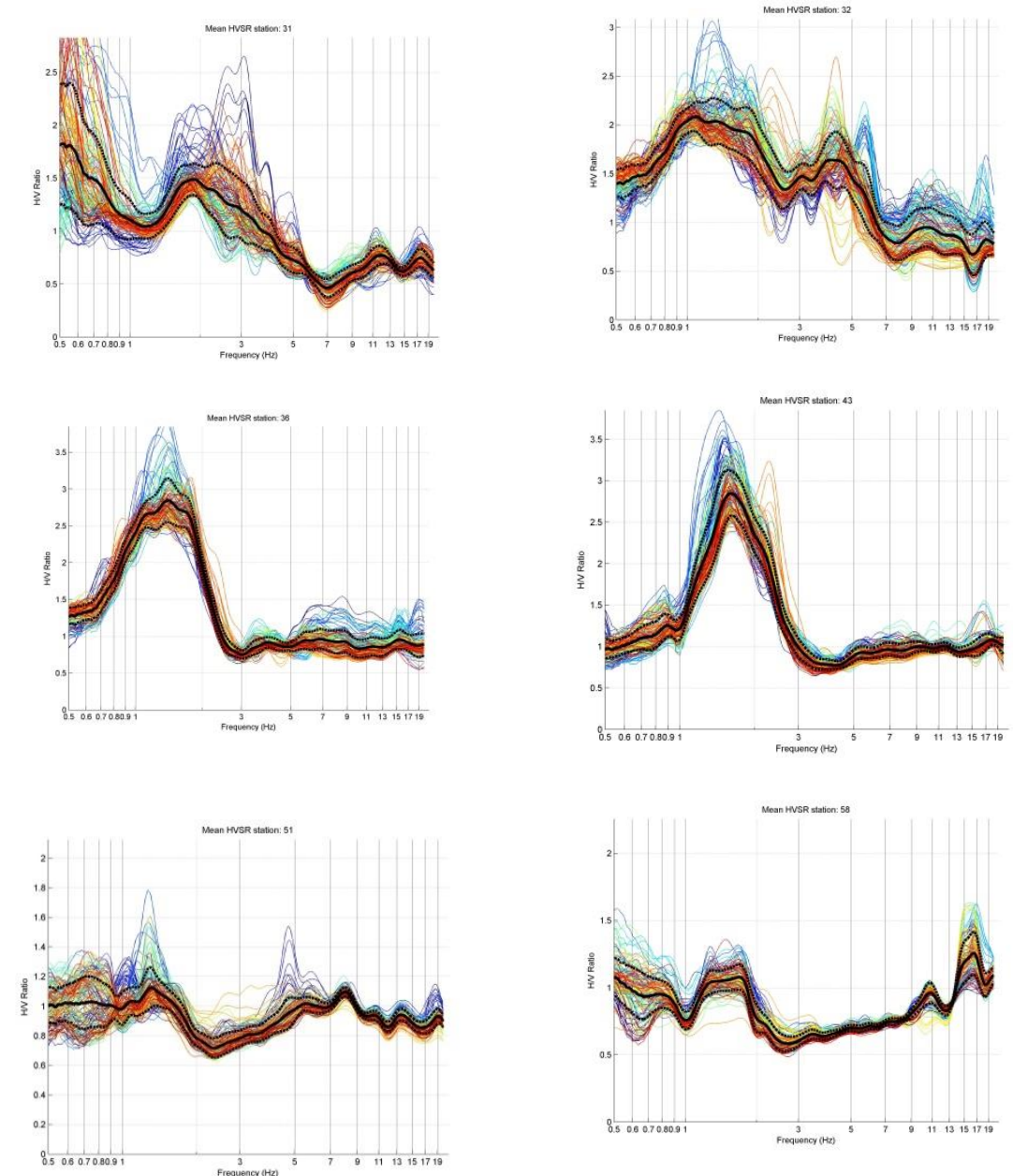

Figure 3 - Mean HVSRs for the Rio stations. The solid black line is the mean HVSR, the two black dashed lines are the standard deviation while the coloured lines show the mean hourly HVSRs. 
The dominant peaks were slightly higher than in the Antirio part of the profile, but their higher amplitude did not exceed 3.5 even for the hourly records with the higher values. Regarding the peak reliability criteria, stations 31, 32, 51 and 58 would fail, while for stations 36 and 43 the criteria were generally successful. As in the Antirio stations the stability of the curve's form can also be seen in these stations, as well as the peak persistence in time.

In summary the following observations could be made for the results on the Rio part:

- There are three different types of HVSR curves.

- Stations 31 and 32 show no clear H/V peak but two frequency plateau, where the spectral ratio is higher along the whole frequency area without a clear sharp apparent peak.

- Stations 36 and 43 show the most clear and unique peaks in the whole profile with relatively high amplitudes. Station 36 has an $\mathrm{f}_{0}=1.8 \mathrm{~Hz}$ while 43 a frequency $\mathrm{f}_{0}=1.5 \mathrm{~Hz}$.

- At positions 51 and 58, relatively flat ratio curves with low ratio amplitudes are observed. Even though the amplitudes of the peaks are lower than 1.5, failing the SESAME guidelines criteria, the form of peaks and troughs of the ratio are consistent throughout the duration of the records while the frequency with the higher amplitude may change with time. It should be noted that station 58 displays two distant dominant frequency peaks at $\mathrm{f}=2 \mathrm{~Hz}$ and $\mathrm{f}=17 \mathrm{~Hz}$.

- HVSR ratios with the azimuth

Another result that can be obtained from ambient noise measurements is the variation of the HVSR ratio with azimuth. For every station the average azimuth- frequency- HVSR diagram was calculated taking into account all the hourly records.

\subsubsection{Antirrio}

The Azimuth- HVSR ratio diagrams also change when the geology of the area where the stations are located changes. For stations 30 and 28 the HVSR ratios seem to have almost the same amplitude for all azimuths. While for stations 04, 11 and 18 the HVSR ratio has higher values in certain azimuth directions. Moreover this direction can vary with frequency, as can be seen on e.g. station 11 (Figure 4).

\subsubsection{Rio}

In the case of Rio the azimuth-HVSR ratio does not change notably. Stations 31 and 32 present strong directionality of the HVSR peaks while for station 58 this is mainly observed in the higher frequency peaks $(\sim 17 \mathrm{~Hz})$. For stations 36 and 43 this effect is not as strong. As in the Antirio results, this azimuthal direction of the HVSR peak can vary for different frequencies. Generally the dominant directions are NNE-SSW up to NE-SW except for the higher frequencies of station 58. 

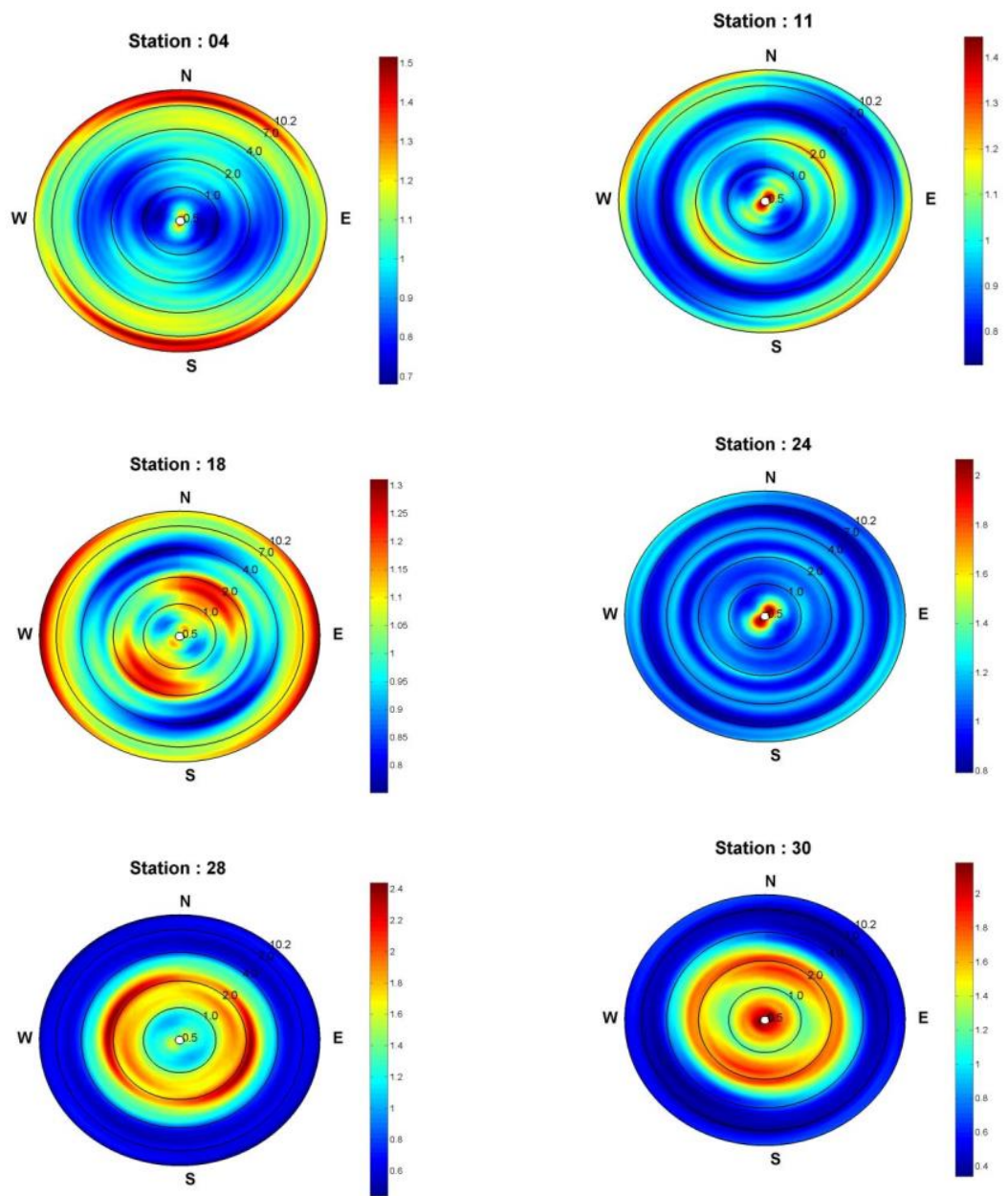

Figure 4 - Mean HVSRs with varying azimuth for the Antirio stations. The colour represents the HVSR ratio frequencies of $0.5 \mathrm{~Hz}$ are near the center of the circle while $10 \mathrm{~Hz}$ towards the perimeter of the circle.

\subsection{HVSR profile}

The HVSR ratio can be used as a preliminary geophysical survey tool. The fundamental frequencies derived from the HVSR ratio can be used for approximating the thickness of the sediments in a basin, even though determining an appropriate value for Vs for the whole top sediment column for Equation 2 can be difficult. In a profile, the relative lateral variation of the fundamental frequency can also be used to delineate the geometry of the top layer rather than its accurate depth.

Figure 5 shows average HVSR ratios along the station's profile as well as two boreholes that were made in the area (C.P.W.L, 1992). For this profile, station 04 was set to position $0 \mathrm{~m}$ and the rest of the stations were positioned along the profile according to increasing distances. In general, the dominant frequency decreases towards the sea, indicating an apparent increase in the thickness of the sediments. At the stations further from the sea (stations 04, 11, 18, 24, 51 and 58) the ratios are relatively flat with weak picks were some higher frequencies (with $\mathrm{f}_{0}$ up to $17 \mathrm{~Hz}$ ) can become dominant. 

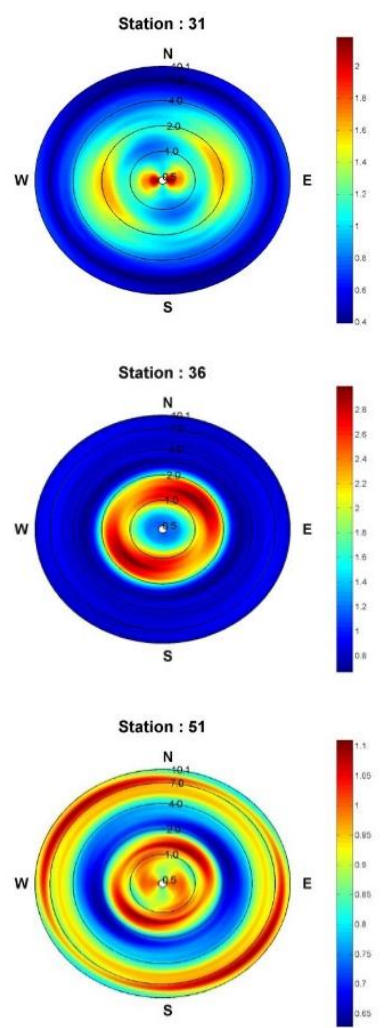
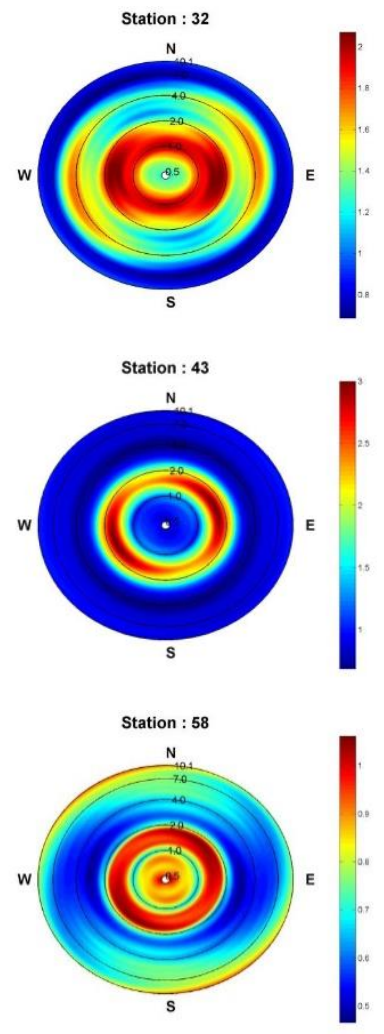

Figure 4 - Average HVSRs with varying azimuth for the Rio stations.

The azimuthal projections of HVSR show that stations with similar characteristics also seem to be geographically close (Figure 5). Also as it can be seen in the case of Antirio, this directionality effect is more prominent at the stations further from the sea. These results could imply that the HVSR azimuth could be related to the geological and geophysical characteristics at the vicinity of the station, such as lithology characteristics or the presence of faults but further investigation is needed.

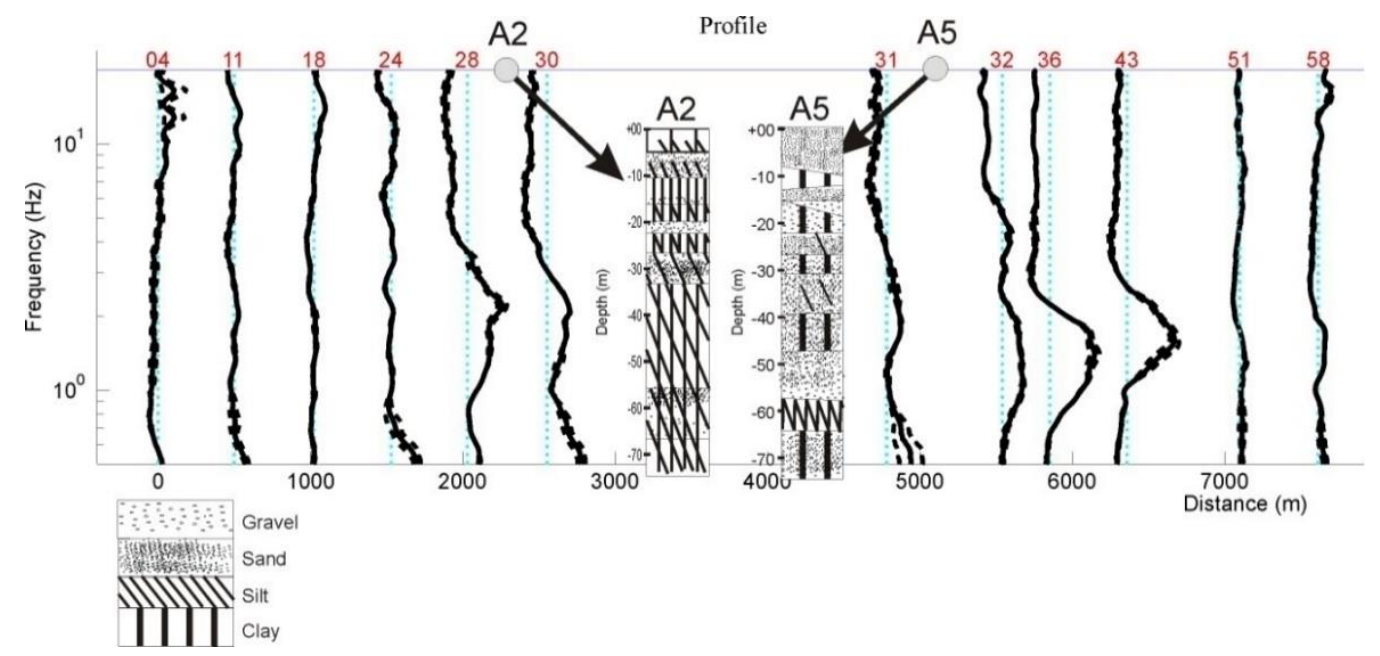

Figure 5 - HVSR ratios placed along the profile, solid black lines show the HVSR ratio, black dashed lines represent \pm 1 standard deviation. Two boreholes are included for comparison. 


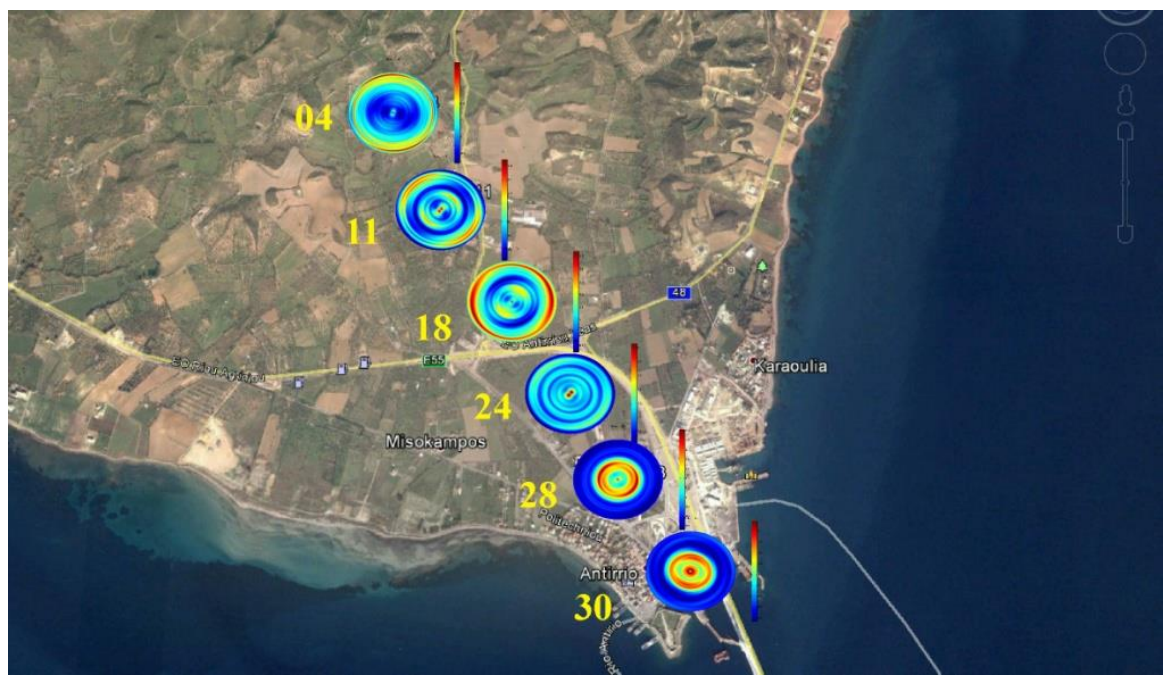

Figure 6 - The average azimuth-HVSR diagrams for the Antirio area. HVSR ratios are up to $20 \mathrm{~Hz}$.

\section{Conclusions}

A study of the HVSR ratio has been made in the Rio Antirio area using recordings of ambient seismic noise. The diagrams of the HVSR have shown that in most recording positions there is no significant seismic amplification with the exception of stations 36 and 43 where a higher HVSR peak is present. For most of the stations the peaks present in the HVSR curve have weak amplitudes and the frequency where the higher value is found can vary with time. But these peaks are present and persistent during the whole recording time. The HVSR when analyzed in relation to the azimuth can show that for some stations the HVSR ratio is consistently higher along preferred directions. The long duration of the recording time, approximately 7 days, indicates that this is mainly due to permanent local conditions such as geology, and tectonics, even though some persistent noise sources such as the sea cannot be ruled out. Finally an attempt to delineate the geometry of the top sedimentary layer was made using the whole spectral ratio curve. Even though the HVSR method is widely used for finding out the peaks of the dominant frequency in an area, under the assumption of a 1-D soil profile, there is potential in extracting more useful information using the whole form of the HVSR curve even in areas where the ratio is relatively weak.

\section{Acknowledgments}

We would like to thank the Patras Seismological laboratory for providing the raw data and the University of Patras', Laboratory of Engineering geology for giving us access to the geotechnical data. We would also like to thank an anonymous reviewer for helpful comments that helped improve the manuscript.

\section{References}

Avallone, A., Briole, P., Agatza-Balodimou, A.M., Billiris, H., Charade, O., Mitsakaki, C., Nercessian, A., Papazissi, K., Paradissis, D. and Veis, G., 2004. Analysis of eleven years of deformation measured by GPS in the Corinth Rift Laboratory area, C. R. Geosci., 336(4-5), 301-311.

C.P.W.L, 1992. Rion Antirrion junction bridge additional geotechnical investigations carried out by the geotechnical engineering section of the central public works laboratory (C.P.W.L), C.P.W.L report. 
Konno, K. and Ohmachi, T., 1998. Ground-motion Characteristics Estimated from Spectral Ratio between Horizontal and Vertical Components of Microtremor, Bull. Seismol. Soc. Am, 88, 228-241.

Nakamura, Y., 1989. A method for Dynamic Characteristics Estimation of Subsurface using Microtremor on the Ground Surface, Quarterly Report of Railway Technical Research Institute (RTRI), 30, 1.

Nakamura, Y., 1997. Seismic Vulnerability Indices for Ground and Structures Using Microtremor, World Congress on Railway Research in Florence, Italy, November 1997.

Oliveto, A., Mucciarelli, M. and Caputo, R. 2004. HVSR prospecting in multi-layered environments: An example from the Tyrnavos Basin (Greece), J. Seism., 8, 395-406.

Paraskevopoulos, P., 2015. HVSRmat v 0.5 User's manual, 10 pp.

SESAME, 2004. Guidelines for the implementation of the H/V spectral ratio technique on ambient vibrations: measurements, processing and interpretation, SESAME report Deliverable-D23, $62 \mathrm{pp}$.

Tselentis, G.-A., Serpetsidaki, A., Martakis, N., Sokos, E., Paraskevopoulos, P. and Kapotas, S., 2007. Local high resolution passive seismic tomography and Kohonen neural networks, application at the Rio-Antirrio Strait, Central Greece, Geophysics, 72(4), B93-B106. 